\title{
DISSIPATIVE STRUCTURES IN EXTREMELY DILUTED SOLUTIONS OF HOMEOPATHIC MEDICINES: A MOLECULAR MODEL BASED ON PHYSICO-CHEMICAL AND GRAVIMETRIC EVIDENCES
}

\author{
V. ELIA \& E. NAPOLI \\ Department of Chemistry, University "Federico II" of Naples, Italy.
}

\begin{abstract}
Conductometric and pHmetric titrations of extremely diluted solutions (EDS) were performed by adding $\mathrm{NaOH}$ or $\mathrm{HCl}$ solutions at concentrations between $1 \times 10^{-2}$ and $1 \times 10^{-3} \mathrm{M}$. The aim of this work is to obtain further confirmation of the hypothesized presence, in the EDS, of molecular aggregates of water molecules. The measurements on the EDS evidenced some relevant differences compared to those on solutions with just water as solvent. The conductivity and the $\mathrm{pH}$ variations caused by adding the titrant, namely $\mathrm{NaOH}$ or $\mathrm{HCl}$ were markedly different to those of the control solutions. We suppose that the preparation procedure of the EDS could produce non-equilibrium changes in the supramolecular structure of water. The experimental results were interpreted by considering the interactions that can take place between the $\mathrm{OH}^{-}$or $\mathrm{H}_{3} \mathrm{O}^{+}$and the hypothesized molecular aggregates of water molecules, i.e. dissipative structures. A qualitative comparison was made about the nature of the driving force that leads to the formation of the complexes between the two ions deriving from water and the molecular aggregates of water molecules (dissipative structures). In this work we have introduced a new methodology to study the EDS and to have more information about the presence of the dissipative structures, i.e. the gravimetric analysis. We evaporate a known quantity of the EDS at $90^{\circ} \mathrm{C}$ for 36-48 hours, and compare the obtained quantity of solid with the expected one given the chemical composition of the liquid, obtained via analytical measurements: atomic absorption and ICP mass. We systematically obtain that the experimental results are higher than the expected ones. The ratio of the obtained and expected results is about 3:2, putting in evidence that some water remains stable even after a very long treatment at $90^{\circ} \mathrm{C}$. A linear correlation is obtained between the solid weight in excess, i.e. the difference between the experimental weight of the solid obtained after the complete evaporation of bulky water and the expected weight according to the chemical composition, $\Delta \mathrm{mg}$, and the conductivity in excess, namely the difference between the experimental conductivity and the expected one according to the chemical composition, $\chi_{\mathrm{r}}^{\mathrm{E}}$.

Key words: conductometry, pHmetry, dissipative structures, gravimetric analysis, homeopathic dilutions.
\end{abstract}

\section{INTRODUCTION}

In the two most recent articles $[1,2]$ we put forth a new interpretation of conductometric and pHmetric titrations, performed on EDS, using $\mathrm{HCl}$ or $\mathrm{NaOH}$ as titrant. That new molecular interpretation better explains the calorimetric titrations done in the past, employing a flow-mix microcalorimetry technique [3, 4]. In both kinds of titrations (acids or bases as titrants) a strong interaction with the dissipative structures [5-7], i.e. the water molecules aggregates, is supposed, because of the measured exothermic effects. As soon as all the molecular aggregates have formed complexes with the added ions, the conductometric response shows a net increase of specific conductivity, due to added $\mathrm{H}_{3} \mathrm{O}^{+}$or $\mathrm{OH}^{-}$ions, that are free, while the calorimetric response is constant $[8,9]$. The favorable interaction between $\mathrm{H}_{3} \mathrm{O}^{+} \mathrm{or} \mathrm{OH}^{-}$and the molecular aggregates of water molecules is due, probably, to steric hindrance and chemical affinity with the aggregates.

As a matter of fact, in the pHmetric titrations using $\mathrm{HCl}$ as titrant, the $\mathrm{pH}$ variations are much lower in the EDS systems than in the control. Namely the pHs are always higher than in the control, until all the aggregates have formed complexes with the added $\mathrm{H}^{+}$, indicating a common mechanism across the conductometric, pHmetric and calorimetric titrations. The reverse happens when the titrant is $\mathrm{NaOH}$ solutions. 
Hence the whole phenomenology hints at the presence of dissipative structures with a 'concentration' that can be roughly determined using conductometric and pHmetric titrations with strong acids or bases. The conductometric, pHmetric and calorimetric results of the titrations are very consistent with the hypothesis of the formation of complexes of aggregates and $\mathrm{H}_{3} \mathrm{O}^{+} \mathrm{Or} \mathrm{OH}^{-}$ions.

In previous articles [3, 4], using calorimetric techniques we evidenced the favorable interaction between the EDS and the two ions that derive from water, i.e. exothermic heat of mixing in calorimetric titrations with $\mathrm{HCl}$ or $\mathrm{NaOH}$. Those titrations put in evidence the 'reactivity' of the EDS with solutions of acids and/or bases at different concentrations. The EDS display a different physico-chemical behavior compared to their solvent [1-3, 8-18]. They behave as complex systems, influenced by peculiar aspects of the preparation technique, as well as by the storage conditions [19-28]. The physico-chemical results led us to think of a supramolecular organization occurring in the water of the EDS. Namely the existence of some aggregates of water molecules, giving rise to a phenomenology that depends on the age of the samples and their storage volume, in a way that is not explained by classical thermodynamics, but can rather be explained by the thermodynamics of far-from-equilibrium systems or of irreversible processes [1-4, 8-18, 29]. The agitation step might be responsible for the emergence of the novel behavior that we witnessed, by triggering the formation of dissipative structures [5-7].

The conductometric titrations measurements and the pHmetric ones evidenced some relevant differences between the EDS and the water solvent. It must be underlined that, for example, the conductivity of an EDS is largely higher than the one expected given its chemical composition. In this work we introduce gravimetric analysis as a means to evidence the presence of aggregates of water molecules that are very stable to thermal treatments, up to $90^{\circ} \mathrm{C}$. We simply evaporate the bulky water from EDS solutions and compare the weight of the obtained solid with the expected one given the chemical composition of the liquid. The ratio of the obtained and expected one is about 3:2 putting in evidence that some water remains stable up to $90^{\circ} \mathrm{C}$. Furthermore, by refilling the container from which the bulky water was evaporated, we are able to almost restore the previous physico-chemical behavior, e.g. the conductivity of the EDS after the refilling process was still higher than one can predict from the chemical composition.

\subsection{Materials}

\section{EXPERIMENTAL}

The solutes, produced by Carlo Erba, Sigma or Fluka, were of the highest purity available commercially. The 'extremely diluted solutions' were prepared using, as solvent, a solution of sodium bicarbonate and/or silicic acid, at low and known concentrations $\left(5 \times 10^{-5} / 1 \times 10^{-4} \mathrm{~mol} \mathrm{~L}^{-1}\right)$. The EDS were prepared and stored in laboratory glass containers treated with an $\mathrm{H}_{2} \mathrm{SO}_{4} / \mathrm{K}_{2} \mathrm{Cr}_{2} \mathrm{O}_{7}$ solution. After that treatment, the containers were rinsed with twice distilled water, until the electric conductivity of the rinsing water reached a value of $1.2 \pm 0.2 \mu \mathrm{S} \mathrm{cm}^{-1}$, the same as twice distilled water.

\subsection{Procedures}

The EDS preparation follows the typical technique of homeopathic medicine proposed by Hahnemann [30] that essentially implies the iteration of two steps: dilution (centesimal or decimal) and 'dynamization'. The process of 'dynamization' consists of violent agitations (succussions) of the solution, by means of a mechanical apparatus.

For a centesimal dilution, the starting point is a $1 \%$ in mass solution: As an example, to prepare a centesimal dilution of sodium chloride $(\mathrm{NaCl}), 1 \mathrm{~g}$ of $\mathrm{NaCl}$, is added to $99 \mathrm{~g}$ of solvent (dilution step). The solution is then subject to the process of 'dynamization' (succussion step), consisting in a violent 
shaking by means of a mechanical apparatus (DYNA HV 1 by Debofar N.V.S.A. Belgium). The final solution is called ' 1 centesimal hahnemannian' or $1 \mathrm{CH}$ for short. So in the preceding example, $\mathrm{NaCl}$ $1 \mathrm{CH}$ was obtained. In order to prepare the 2 centesimal hahnemannian $(\mathrm{NaCl} 2 \mathrm{CH}), 1 \mathrm{~g}$ of the $1 \mathrm{CH}$ solution is added to $99 \mathrm{~g}$ of solvent, and the resulting solution is 'dynamized'. The dilution and succussion steps are iterated until the desired degree of dilution is met. The studied EDS were single dilutions or a mix of many solutions with different active principles and dilution degrees $(\mathrm{CH})$, because we needed high quantities of EDS for the experimental procedures of titration.

The conductometric titrations were performed measuring the specific electrical conductivity of a solution of EDS $(1.5-10 \mathrm{~mL})$ as a function of the volume of added $\mathrm{HCl}$ or $\mathrm{NaOH}$, and thus of the concentration of the added titrant in the final solution. Likewise, in the pHmetric titrations we measured the $\mathrm{pH}$ of the solution when varying the quantity of the added titrants. The same titration procedure was employed for the control solutions, namely solutions of sodium bicarbonate at the same concentration of the EDS solutions.

Samples of two different solutes were used: AA: Asernicum Album $\left(\mathrm{As}_{2} \mathrm{O}_{3}\right)$; 2,4D: Dichlorophenoxicacethic acid; the samples labeled GP (glass powder) [2,31] were obtained by putting in contact, for a period of several months, glass powder of the employed vials and twice distilled water.

The aim was to simulate a solution containing the components of the glass $\left(\mathrm{Na}_{2} \mathrm{O}, \mathrm{SiO}_{2}, \mathrm{~B}_{2} \mathrm{O}_{3}\right.$, $\mathrm{Al}_{2} \mathrm{O}_{3}$ ), thus a very similar composition to that of the EDS, to gain some insight into the behavior of the control in the titration procedure with $\mathrm{HCl}$ or $\mathrm{NaOH}$ solutions, and on the weight to expect after the evaporation process of an ordinary chemical solution or one containing dissipative structures (EDS).

\subsection{Analytical determination of impurities}

The sodium concentration was determined through the spectroscopic method of atomic absorption, using a Spectra A Varian instrument. Before measuring the samples, the necessary calibration curve was obtained using standard solutions. To prepare the standard solutions, $\mathrm{NaCl}$ was dissolved in water and diluted to 1 liter, to obtain $1000 \mu \mathrm{g} / \mathrm{mL}$ Na. The working conditions were: Lamp current: $5 \mathrm{~mA}$; Fuel: acetylene; Support: air; Flame stoichiometry: oxidizing. The wavelength used, chosen on the basis of the concentration range of sodium, was $589.6 \mathrm{~nm}$. Sodium is partially ionized in the air-acetylene flame. To suppress the ionization, some potassium chloride solution was added, to produce a final concentration of $2000 \mu \mathrm{g} / \mathrm{mL}$ in every solution, including the blank. The $\mathrm{Si}, \mathrm{Al}$ and B concentrations were determined through the ICP-mass method using an Agilent 7500 ICP-MS instrument.

\subsection{Evaporation process}

EDS solutions that undergo the evaporation process are kept in vials of about $40 \mathrm{ml}$ that are then placed in a stove at $90^{\circ} \mathrm{C}$ for $36-48$ hours, until a solid deposit is obtained, caused by the presence of impurities in the glass (sodium carbonate, silicic acid, boric acid, aluminum trioxide). The vials undergo several cycles of heating in the stove at the temperature of $90^{\circ} \mathrm{C}$, until every vial reaches a steady weight. The weight can be considered constant when the weight difference between a cycle and the following varies in the range of $\pm 0.1 \mathrm{mg}$. This range is equal to the sensitivity of the used analytic balance (Gibertini E $42 \mathrm{~S}$ ). The solid deposit after the evaporation of bulk water reaches a constant weight after about 12 hours of stasis at a temperature of $25 \pm 0.5^{\circ} \mathrm{C}$. The refilling process consists in adding twice-distilled water to the solid deposit on the bottom of the vial. The water is added in a quantity equal to the weight of the solution before the evaporation process. The measurements show that electrical conductivity slowly grows during the following 24-48 hours, and then it reaches a constant value that is very close to the one measured before the evaporation process (from zero to 
$20 \%$ less). We set forth a hypothesis on the chemical species of the deposit that result from the evaporation process. The hypothesis was tested on GP solutions (see the procedures section) that are considered control solutions since they do not contain dissipative structures. By hypothesizing that the chemical species in the solid deposit are $\mathrm{Na}_{2} \mathrm{CO}_{3}, \mathrm{H}_{4} \mathrm{SiO}_{4}, \mathrm{H}_{2} \mathrm{BO}_{3}$ and $\mathrm{Al}_{2} \mathrm{O}_{3}$ (see Table 2), we obtain an expected weight that matches the actual experimental weight. The analysis of the impurities content released by the glass of the containers has been carried out using atomic absorption spectroscopy for the analysis of the Na concentration and ICP-MS to determine the concentration of $\mathrm{Si}, \mathrm{Al} \mathrm{B}$ (see Analytical determination of impurities section).

\section{RESULTS AND DISCUSSION}

In two previous articles [1,2] we reported the results of conductometric and pHmetric titrations of EDS using $\mathrm{HCl}$ or $\mathrm{NaOH}$ solutions as titrants. The aims of those works were to obtain further confirmation of the hypothesized presence, in the EDS, of molecular aggregates of water molecules.

The measurements on the EDS evidenced some relevant differences compared to those in solutions with just water as solvent containing solutes (impurities) deriving from the glass containers.

The experimental results were interpreted by considering the interaction that takes place between the $\mathrm{H}_{3} \mathrm{O}^{+}$and $\mathrm{OH}^{-}$ions and the hypothesized molecular aggregates of water molecules or aqueous nanostructures [32], i.e. dissipative structures. A qualitative comparison was made about the nature of the driving force that leads to the formation of complexes between the two ions, $\mathrm{H}_{3} \mathrm{O}^{+}$and $\mathrm{OH}^{-}$, and the dissipative structures.

The qualitative conclusion is that for $\mathrm{OH}^{-}$the binding process has a driving force of enthalpic nature, while for $\mathrm{H}_{3} \mathrm{O}^{+}$the opposite happens, the driving force being of entropic nature. The whole phenomenology hints at the presence of dissipative structures with a 'concentration' that can be roughly determined using conductometric and pHmetric titrations with strong acids or bases.

The favorable interaction between $\mathrm{H}_{3} \mathrm{O}^{+}$or $\mathrm{OH}^{-}$and the molecular aggregates of water molecules is due, probably, to steric hindrance and chemical affinity with the aggregates. The very complex phenomenology described is, however, self-consistent with the existence of molecular aggregates of water molecules, what we call 'dissipative structures', with a strong chemical affinity with the $\mathrm{H}_{3} \mathrm{O}^{+}$ and $\mathrm{OH}^{-}$ions.

Consequently they form very stable complexes (binding phenomena). From a calorimetric point of view, in this hypothesis we must naturally expect an exothermic phenomenon, as the one actually observed. All of the different physico-chemical procedures that were employed seem to lead to only one possible hypothesis, that related to the binding phenomena, and to the existence of a single cause in the results of those three very different methodologies: a transport phenomenon (conductometry) and two phenomena tied to thermodynamic equilibrium (pHmetry and calorimetry).

The good self-consistency of this interpretation prompted us to try new methodologies that would help gather new information about the properties of the aggregates, such as the gravimetric analysis approach. We supposed that the strong interaction between $\mathrm{H}_{3} \mathrm{O}^{+}$or $\mathrm{OH}^{-}$would also be possible between the $\mathrm{OH}$ functional groups of alcohols, carbohydrates, bases and the functional groups of the acids. It is interesting to note that the EDS are used in homeopathic medicines that typically uses hydroalcoholic mixtures or solid supports made of sugar (the globules).

As we said before our EDS are water solutions with a very low quantity of impurities deriving from the glass containers $\left(\mathrm{H}_{4} \mathrm{SiO}_{4}, \mathrm{H}_{2} \mathrm{BO}_{3}, \mathrm{Al}_{2} \mathrm{O}_{3}\right.$ and sodium bicarbonate $\left.\mathrm{NaHCO}_{3}\right)$. All these substances are able, in principle, to produce very strong interactions with the dissipative structures. The presence of these kinds of impurities probably leads to a favorable situation for the stability of the EDS in time or in the presence of thermal excursions.

The hypothesis is that dissipative structures can bind with the impurities so as to gain a very strong stability, also in the absence of bulky water. 
We carried out several experiments of evaporation of the bulky water with very different pressure and temperature conditions. All the experiments show a very high stability of the system, also at very high temperatures. For that reason we chose to operate at atmospheric pressure and with a temperature of $90^{\circ} \mathrm{C}$, for the rapidity of evaporation under those conditions. To indirectly prove that such a harsh treatment does not alter the physico-chemical properties of the EDS, we refilled the glass container after the evaporation and performed electrical conductivity measurements. The variations of conductivity after evaporation and the refilling procedure are very low (about 20\%) and statistically negative.

Figs 1a and $\mathrm{b}$ show the excess conductivity of the refilled samples as a function of the excess conductivity of the initial solutions. This way we can correlate the concentration of dissipative

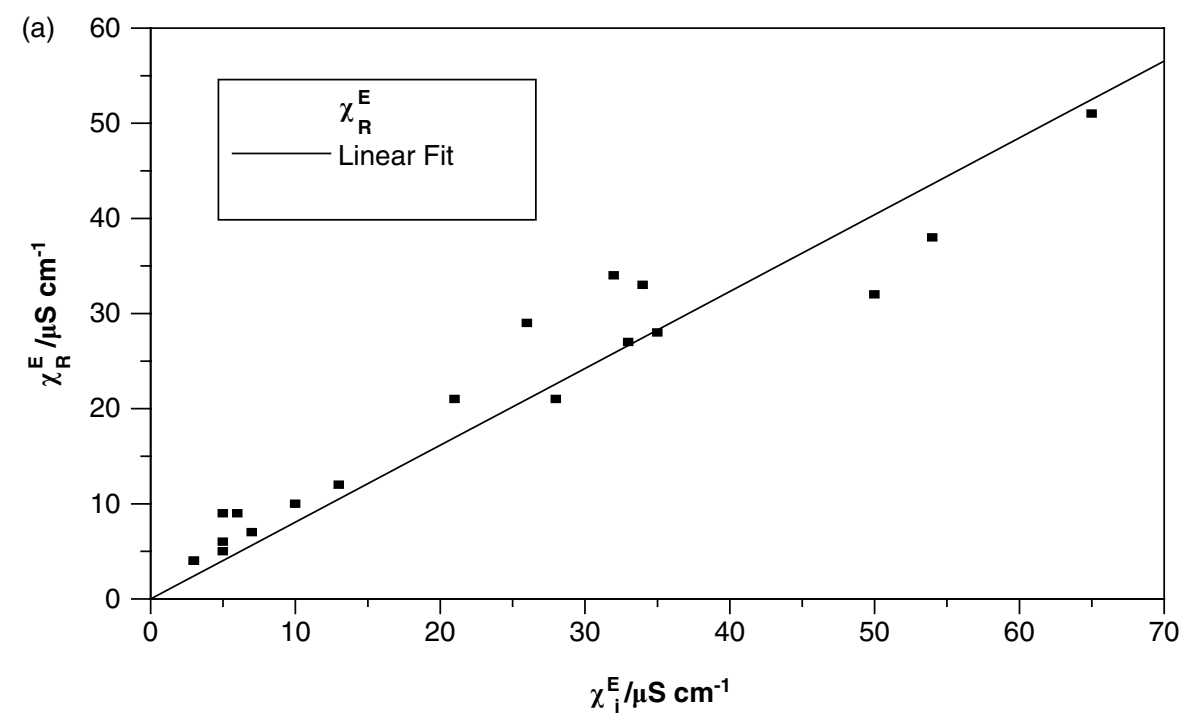

(b)

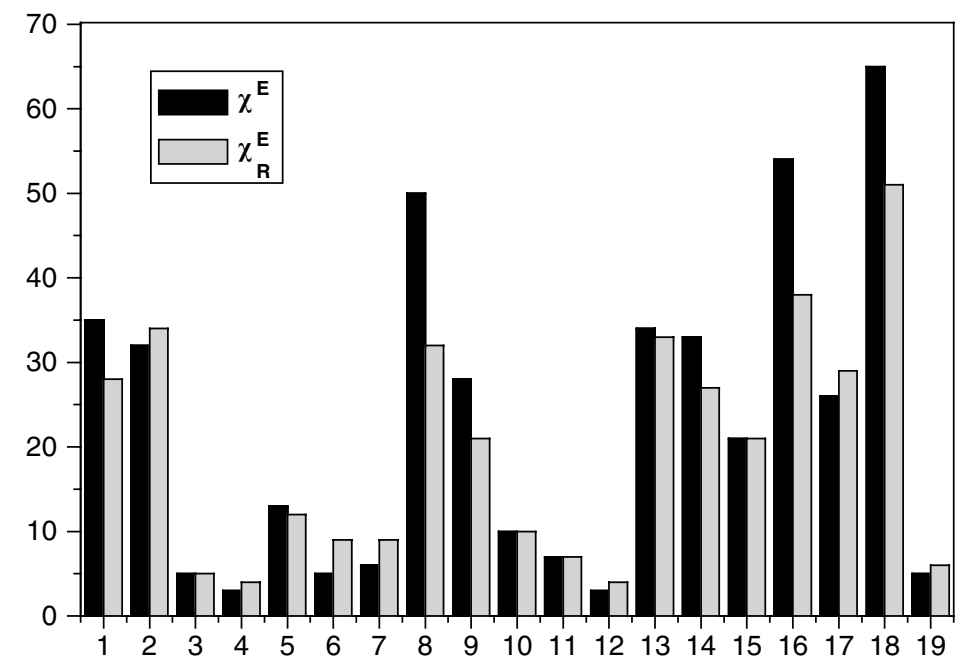

Figure 1: (a) The linearly correlated quantities, $\chi_{\mathrm{R}}^{\mathrm{E}}$, the conductivity after the refilling procedure and $\chi^{\mathrm{E}}{ }_{\mathrm{i}}$, the initial conductivity. Parameters of the linear interpolation $y=b x: b=0.808 \pm$ $0.03, \mathrm{R}=0.966 \mathrm{SD}=4.37, N=19$. Origin Pro 7.5. (b) The histogram of the linearly correlated quantities of Fig. 1a. 
structures in the initial EDS and in the refilled one. It is interesting to underline that after the refilling procedures it takes several days before the systems reach a stable conductivity value, probably because of the slow kinetics of the dissolution process of the obtained solid.

Something inside the EDS is able to reproduce the physico-chemical properties after the refilling procedures!

We supposed that the aggregates of water molecules can stabilize themselves via strong interaction with the impurities and that, also at high temperature, the water aggregates do not evaporate.

We estimated the weight of water aggregates contained in $20 \mathrm{~mL}$, the quantity of solution that we usually evaporate. To do that we use the concentration of the aggregates obtained via conductometric titration using $\mathrm{HCl}$ as titrant. In the simplified hypothesis of a one-to-one binding process, aggregates of about 10-20 water molecules should produce a weight in excess of about 1-2 mg, a very measurable quantity.

We performed about 30 preliminary experiments of evaporation obtaining almost every time an experimental weight in excess. After those tests, further experiments were conducted in a very careful way and the results are reported in Table 1.

Table 1 reports the concentration $\mathrm{M}(\mathrm{mol} / \mathrm{L})$ of $\mathrm{Al}_{2} \mathrm{O}_{3}, \mathrm{H}_{2} \mathrm{BO}_{3}, \mathrm{H}_{4} \mathrm{SiO}_{4}$ and $\mathrm{Na}_{2} \mathrm{CO}_{3}$; the initial conductivity, $\chi_{\mathrm{i}}\left(\mu \mathrm{S} \mathrm{cm}^{-1}\right)$, i.e. the conductivity of the sample before the evaporation procedure; the excess conductivity $\chi^{\mathrm{E}}\left(\mu \mathrm{S} \mathrm{cm}^{-1}\right)$ of the sample, i.e. the difference between the initial conductivity and that due to the chemical content; the excess conductivity of the refilled sample $\chi_{\mathrm{R}}^{\mathrm{E}}\left(\mu \mathrm{S} \mathrm{cm}{ }^{-1}\right)$,

Table 1: M molarity (mol L-1); initial conductivity $\chi_{\mathrm{i}}\left(\mu \mathrm{S} \mathrm{cm}{ }^{-1}\right)$; the excess conductivity $\chi^{\mathrm{E}}(\mu \mathrm{S}$ $\left.\mathrm{cm}^{-1}\right)$ of the sample; the excess conductivity of the refilled sample $\chi_{\mathrm{R}}^{\mathrm{E}}\left(\mu \mathrm{sm}^{-1}\right)$; the expected weight from chemical analysis, $\mathrm{mg}_{\text {expc }}(\mathrm{mg})$; the experimentally determined weight, $\mathrm{mg}_{\text {exper }}(\mathrm{mg})$ and the $\Delta \mathrm{mg}(\mathrm{mg})$, i.e. $\mathrm{mg}_{\text {exper }}-\mathrm{mg}_{\text {expc }}$ for EDS samples.

\begin{tabular}{|c|c|c|c|c|c|c|c|c|c|}
\hline $\begin{array}{l}\mathrm{M} \mathrm{mol} \mathrm{L} \mathrm{L}^{-1} \\
\left(\mathrm{Al}_{2} \mathrm{O}_{3}\right)\end{array}$ & $\begin{array}{c}\mathrm{M} \text { mol L L-1 } \\
\left(\mathrm{H}_{2} \mathrm{BO}_{3}\right)\end{array}$ & $\begin{array}{c}\mathrm{M} \mathrm{mol} \mathrm{L}^{-1} \\
\left(\mathrm{H}_{4} \mathrm{SiO}_{4}\right)\end{array}$ & $\begin{array}{l}\mathrm{M} \mathrm{mol} \mathrm{L}{ }^{-1} \\
\left(\mathrm{Na}_{2} \mathrm{CO}_{3}\right)\end{array}$ & $\begin{array}{c}\mu \mathrm{S} \mathrm{cm}{ }^{-} \\
\left(\chi_{\mathrm{i}}\right)\end{array}$ & $\begin{array}{c}\mu \mathrm{Sc} \mathrm{m}^{-1} \\
\left(\chi^{\mathrm{E}}\right)\end{array}$ & $\begin{array}{c}\mu \mathrm{S} \mathrm{cm}^{-1} \\
\left(\chi_{\mathrm{R}}^{\mathrm{E}}\right)\end{array}$ & $\begin{array}{c}\mathrm{mg} \\
\left(\mathrm{mg}_{\text {expec }}\right)\end{array}$ & $\begin{array}{c}m g \\
\left(\mathrm{mg}_{\text {exper }}\right)\end{array}$ & $\begin{array}{c}\mathrm{mg} \\
(\Delta \mathrm{mg})\end{array}$ \\
\hline $4.0 \times 10^{-6}$ & $8.1 \times 10^{-5}$ & $7.4 \times 10^{-6}$ & $7.0 \times 10^{-4}$ & 100 & 35 & 28 & 0.9 & 2.3 & 1.4 \\
\hline $2.0 \times 10^{-6}$ & $4.0 \times 10^{-4}$ & $5.1 \times 10^{-6}$ & $2.7 \times 10^{-4}$ & 57 & 32 & 34 & 0.8 & 2.2 & 1.4 \\
\hline $3.3 \times 10^{-6}$ & $1.1 \times 10^{-4}$ & $2.5 \times 10^{-6}$ & $5.0 \times 10^{-5}$ & 10 & 5 & 5 & 0.2 & 0.4 & 0.2 \\
\hline $7.1 \times 10^{-7}$ & $2.6 \times 10^{-4}$ & $1.4 \times 10^{-5}$ & $1.1 \times 10^{-4}$ & 13 & 3 & 4 & 0.4 & 0.8 & 0.4 \\
\hline $5.2 \times 10^{-7}$ & $3.1 \times 10^{-4}$ & $3.7 \times 10^{-6}$ & $1.6 \times 10^{-4}$ & 28 & 13 & 12 & 0.4 & 1.3 & 0.9 \\
\hline $1.2 \times 10^{-7}$ & $2.5 \times 10^{-4}$ & $2.8 \times 10^{-6}$ & $1.1 \times 10^{-4}$ & 21 & 5 & 9 & 0.3 & 0.6 & 0.3 \\
\hline $3.2 \times 10^{-7}$ & $1.4 \times 10^{-4}$ & $2.4 \times 10^{-6}$ & $8.4 \times 10^{-5}$ & 13 & 6 & 9 & 0.2 & 0.8 & 0.6 \\
\hline $1.2 \times 10^{-6}$ & $3.9 \times 10^{-4}$ & $1.0 \times 10^{-6}$ & $6.6 \times 10^{-4}$ & 130 & 50 & 32 & 1.4 & 2.7 & 1.3 \\
\hline $2.9 \times 10^{-5}$ & $1.2 \times 10^{-4}$ & $6.8 \times 10^{-7}$ & $2.4 \times 10^{-4}$ & 50 & 28 & 21 & 0.4 & 1.5 & 0.9 \\
\hline $5.1 \times 10^{-5}$ & $1.1 \times 10^{-4}$ & $7.7 \times 10^{-4}$ & $2.4 \times 10^{-4}$ & 32 & 10 & 10 & 0.4 & 0.7 & 0.3 \\
\hline $4.1 \times 10^{-7}$ & $1.2 \times 10^{-4}$ & $7.8 \times 10^{-7}$ & $1.0 \times 10^{-4}$ & 16 & 7 & 7 & 0.3 & 0.5 & 0.2 \\
\hline $1.2 \times 10^{-6}$ & $8.4 \times 10^{-5}$ & $6.8 \times 10^{-7}$ & $8.4 \times 10^{-5}$ & 10 & 3 & 4 & 0.2 & 0.4 & 0.2 \\
\hline 0 & $2.9 \times 10^{-4}$ & 0 & $2.2 \times 10^{-4}$ & 54 & 34 & 33 & 0.6 & 2.3 & 1.7 \\
\hline 0 & $2.9 \times 10^{-4}$ & 0 & $2.3 \times 10^{-4}$ & 54 & 33 & 27 & 0.6 & 2.4 & 1.8 \\
\hline $1.9 \times 10^{-6}$ & $2.9 \times 10^{-4}$ & $6.5 \times 10^{-7}$ & $2.2 \times 10^{-4}$ & 42 & 21 & 21 & 0.6 & 1.6 & 1.0 \\
\hline 0 & $3.7 \times 10^{-4}$ & $8.7 \times 10^{-7}$ & $6.2 \times 10^{-4}$ & 112 & 54 & 38 & 1.1 & 3.5 & 2.4 \\
\hline $1.9 \times 10^{-6}$ & $3.2 \times 10^{-4}$ & $6.4 \times 10^{-7}$ & $2.0 \times 10^{-4}$ & 45 & 26 & 29 & 0.6 & 2.7 & 2.1 \\
\hline $1.7 \times 10^{-7}$ & $4.3 \times 10^{-4}$ & $7.8 \times 10^{-7}$ & $6.4 \times 10^{-4}$ & 122 & 65 & 51 & 1.1 & 4.3 & 3.2 \\
\hline 0 & $8.2 \times 10^{-5}$ & $6.2 \times 10^{-7}$ & $8.1 \times 10^{-5}$ & 11 & 5 & 6 & 0.2 & 0.5 & 0.3 \\
\hline
\end{tabular}


i.e. the difference between the conductivity of the refilled sample and that due to the chemical contents; the expected weight from chemical analysis, $\operatorname{mg}_{\text {expc }}(\mathrm{mg})$; the experimentally determined weight, $\mathrm{mg}_{\text {exper }}(\mathrm{mg})$ and the $\Delta \mathrm{mg}(\mathrm{mg})$.

The weights after evaporating about $20 \mathrm{~mL}$ of EDS are in effect of the order of magnitude of milligrams. The nature of the EDS is always a mix of various active principles or dilution degrees $(\mathrm{CH})$.

Table 2 reports the concentration $\mathrm{M}(\mathrm{mol} / \mathrm{L})$ of $\mathrm{Al}_{2} \mathrm{O}_{3}, \mathrm{H}_{2} \mathrm{BO}_{3}, \mathrm{H}_{4} \mathrm{SiO}_{4}$ and $\mathrm{Na}_{2} \mathrm{CO}_{3}$; the initial conductivity, i.e. the conductivity before the evaporation procedure, $\chi_{\mathrm{i}}\left(\mu \mathrm{S} \mathrm{cm} \mathrm{cm}^{-1}\right) ; \mathrm{mg}_{\text {expc }}(\mathrm{mg})$; the experimentally determined weight, $\mathrm{mg}_{\text {exper }}(\mathrm{mg})$ and the $\Delta \mathrm{mg}(\mathrm{mg})$ for three control solutions, GP. The samples labeled GP (glass powder) [2,31] were obtained by putting in contact, for a period of several months, glass powder of the employed vials and twice distilled water.

As shown in Table 1 the experimental weight is always higher than the expected one, two or three times higher. Table 2 shows that the experimental weight is, on the contrary, equal to the expected one within the limits of the experimental error $( \pm 0.1 \mathrm{mg})$. It is interesting to note that the higher the conductivity excess, the higher is the difference between the experimentally determined weight and the expected one. The two quantities are linearly correlated (see Fig. 2).

This stabilizing process of the dissipative structures that exploits the surrounding impurities, and their ability to reproduce the physico-chemical properties after the refilling procedure bears, mutatis mutandis, some similitude to the ability of some simple living systems, such as a bacterium or a protist, to stay in a quiescent state, in environmental condition not favorable to life. The microbial cyst is a resting or dormant stage of a microorganism that helps it to overcome unfavorable environmental conditions. It can be thought of as a state of suspended animation in which the metabolic processes of the cell are slowed down and the cell ceases all activities such as feeding or locomotion. The process of encystment helps the microbe to resist until more suitable conditions are reached. When the encysted microbe finds an environment favorable to its growth and survival, the cyst wall breaks down (excystation) [33]. For example, in the presence of sufficient water they assume their characteristic far-from-equilibrium state, that of dissipative structures.

We can conclude that dissipative structures are water molecule aggregates and are formed in consequence of perturbations of different nature, even low energy ones. They have the capability to exist far from thermodynamic equilibrium for a long time, of the order of magnitude of several years or more [15, 29]. In the absence of bulky water, as for some of the most simple life forms, they reach a quiescent state in which they exploit a strong interaction with hydrophilic substances. This strong interaction helps them to remain in a state in which they do not dissipate energy until sufficient bulky water is at their disposal. Also in this case, as for the simplest life forms, they are able to return to active state, i.e. returning to be dissipative structures, far-from-equilibrium systems.

Table 2: $\mathrm{M}$ molarity $\left(\mathrm{mol} \mathrm{L}^{-1}\right)$; initial conductivity $\chi_{\mathrm{i}}\left(\mu \mathrm{S} \mathrm{cm}^{-1}\right)$; the expected weight from chemical analysis, $\mathrm{mg}_{\text {expec }}(\mathrm{mg})$; the experimentally determined weight, $\mathrm{mg}_{\text {exper }}(\mathrm{mg})$ and the $\Delta \mathrm{mg}(\mathrm{mg})$, i.e. $\mathrm{mg}_{\text {exper }}-\mathrm{mg}_{\text {expec }}$ for GP samples.

\begin{tabular}{lccccccc}
\hline $\begin{array}{l}\mathrm{M} \mathrm{mol} \mathrm{L}^{-1} \\
\left(\mathrm{Al}_{2} \mathrm{O}_{3}\right)\end{array}$ & $\begin{array}{c}\mathrm{M} \mathrm{mol} \mathrm{L}^{-1} \\
\left(\mathrm{H}_{2} \mathrm{BO}_{3}\right)\end{array}$ & $\begin{array}{c}\mathrm{M} \mathrm{mol} \mathrm{L}^{-1} \\
\left(\mathrm{H}_{4} \mathrm{SiO}_{4}\right)\end{array}$ & $\begin{array}{c}\mathrm{M} \mathrm{mol} \mathrm{L}^{-1} \\
\left(\mathrm{Na}_{2} \mathrm{CO}_{3}\right)\end{array}$ & $\begin{array}{c}\mu \mathrm{S} \mathrm{cm}^{-1} \\
\left(\chi_{\mathrm{i}}\right)\end{array}$ & $\begin{array}{c}\mathrm{mg} \\
\left(\mathrm{mg}_{\text {expec }}\right)\end{array}$ & $\begin{array}{c}\mathrm{mg} \\
\left(\mathrm{mg}_{\text {exper }}\right)\end{array}$ & $\begin{array}{c}\mathrm{mg} \\
(\Delta \mathrm{mg})\end{array}$ \\
\hline 0 & $1.8 \times 10^{-3}$ & $1.3 \times 10^{-4}$ & $5.5 \times 10^{-4}$ & 68 & 3.1 & 3.1 & 0 \\
0 & $8.2 \times 10^{-5}$ & 0 & $4.2 \times 10^{-5}$ & 9 & 0.2 & 0.3 & 0.1 \\
0 & $6.1 \times 10^{-4}$ & $4.3 \times 10^{-5}$ & $1.8 \times 10^{-4}$ & 18 & 1.0 & 1.2 & 0.2 \\
\hline
\end{tabular}




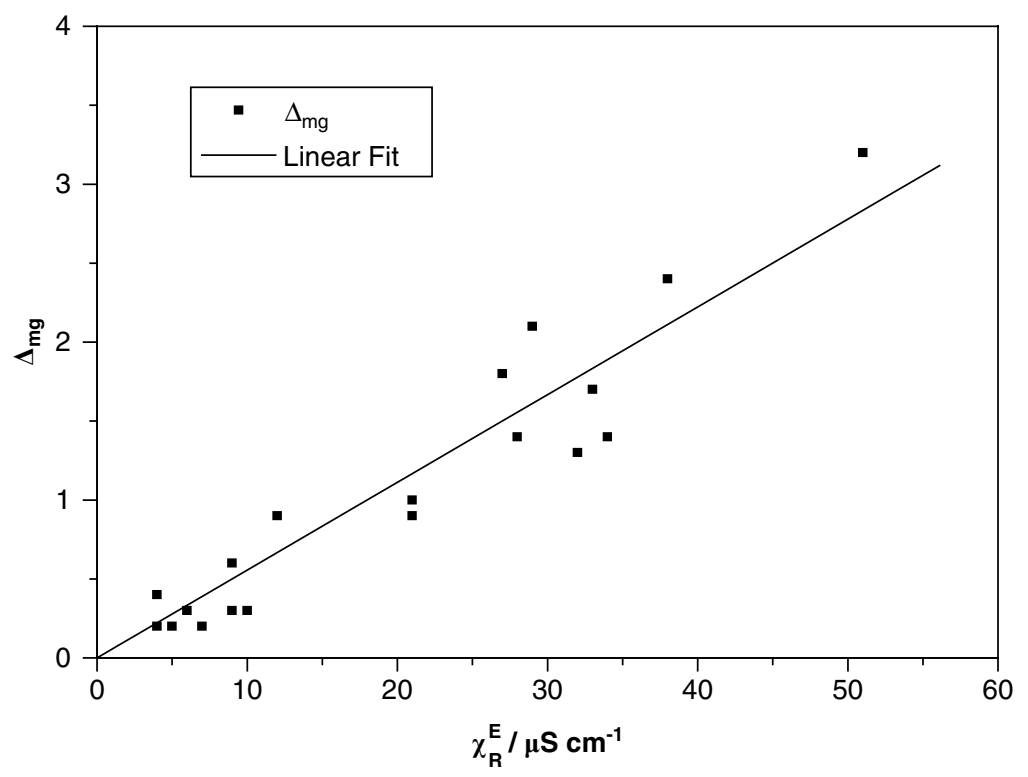

Figure 2: Linearly correlated quantities: $\Delta \mathrm{mg}$, i.e. the difference between the experimental weight and the expected one based on the chemical composition, and $\chi_{\mathrm{R}}^{\mathrm{E}}$, the excess conductivity, i.e. the difference between the experimental conductivity and the expected one according to the chemical composition of the refilled samples. Parameters of the linear interpolation $y=b x: b=0.055 \pm 0.003, \mathrm{R}=0.948 \mathrm{SD}=0.279, N=19$. Origin Pro 7.5.

A new intriguing similitude could be introduced with the mechanism used in homeopathic medicine to offer remedies to the patients via globules of lactose or of a mix of lactose and sucrose imbibed of liquid EDS. When the bulky water evaporates, the dissipative structures stay in a quiescent state until the patient assumes the globules. When the globules enter in contact with the biological liquids they transit to the far-from-equilibrium state of dissipative structures, capable of transmitting the eventually therapeutic information. Given the goal of this research, such consistency in the results of the four different kinds of methodologies is really encouraging!

\section{ACKNOWLEDGMENTS}

This study was financed by a grant from Laboratories Boiron. The authors wish to thank Dr. Silvia Nencioni and Dr. Luigi Marrari for their advice and cooperation.

\section{REFERENCES}

[1] Cacace, C.M, Elia, L., Elia, V., Napoli, E. \& Niccoli, M., Conductometric and pHmetric titrations of extremely diluted solutions using $\mathrm{HCl}$ solutions as titrant. A molecular model. Journal of Molecular Liquids, 146, pp. 122-126, 2009. doi:10.1016/j.molliq.2009.02.012

[2] Elia, V., Napoli, E. \& Niccoli, M., A molecular model of interaction between extremely diluted solutions and $\mathrm{NaOH}$ solutions used as titrant. Conductometric and pHmetric Titrations. Journal of Molecular Liquids, 149, pp. 45-50, 2009. doi:10.1016/j.molliq.2009.06.005

[3] Elia, V. \& Niccoli, M., Thermodynamics of extremely diluted aqueous solutions. Annals of the New York Academy of Sciences, 879, pp. 241-248, 1999. doi:10.1111/j.1749-6632.1999.tb10426.x 
[4] Elia, V., Elia, L., Marchese, M., Montanino, M., Napoli, E., Niccoli, M., Nonatelli, L. \& Savarese, F., Interaction of "extremely diluted solutions" with aqueous solutions of hydrochloric acid and sodium hydroxide, A calorimetric study at $298 \mathrm{~K}$. Journal of Molecular Liquids,130, pp. 15-20, 2007. doi:10.1016/j.molliq.2006.03.053

[5] Nicolis, G., Physics of far-equilibrium systems and self-organization. The New Physics, ed. P. Davies, Cambrige University Press: New York, 1989.

[6] Prigogine, I., 8 December 1977, Time, structure and fluctuations, Nobel Lecture.

[7] Magnani, A., Marchettini, N., Ristori, S., Rossi, C., Rossi, F., Rustici, M., Spalla, O. \& Tiezzi, E., Chemical waves and pattern formation in the 1,2-dipalmitoyl-sn-glycero-3-phosphocholine/ water lamellar system. The Journal of the American Chemical Society, 126, pp. 11406-07, 2004. doi:10.1021/ja047030c

[8] Elia, V. \& Niccoli, M., New Physico-chemical properties of water induced by mechanical treatments. Journal of Thermal Analysis and Calorimetry, 61, pp. 527-537, 2000. doi:10.1023/ A:1010129803824

[9] Elia, V. \& Niccoli, M., New Phisico-chemical properties of extremely diluted solutions. Journal of Thermal Analysis and Calorimetry, 75, pp. 815-836, 2004. doi:10.1023/ B:JTAN.0000027178.11665.8f

[10] Elia, V., Napoli, E., Niccoli, M., Nonatelli, L., Ramaglia, A. \& Ventimiglia, E., New physico-chemical properties of extremely diluted aqueous solutions. A calorimetric and conductivity study at $25^{\circ} \mathrm{C}$. Journal of Thermal Analysis and Calorimetry, 78, pp. 331-342, 2004. doi:10.1023/B:JTAN.0000042179.07858.c8

[11] Elia, V., Marchese, M., Montanino, M., Napoli, E., Niccoli, M., Nonatelli, L., \& Ramaglia, A., Hydrohysteretic phenomenon of "extremely diluted solutions" induced by mechanical treatments. A calorimetric and conductometric study at $25^{\circ} \mathrm{C}$. Journal of Solution Chemistry, $\mathbf{3 4}$, pp. 947-960, 2005. doi:10.1007/s10953-005-6258-3

[12] Elia, V., Elia, L., Cacace, P., Napoli, E., Niccoli, M., \& Savarese, F., Extremely diluted solutions as multi-variables systems: a study of calorimetric and conductometric behaviour as a function of the time parameter. Journal of Thermal Analysis and Calorimetry, 84, pp. 317-323, 2006. doi:10.1007/s10973-005-7266-7

[13] Elia, V., Elia, L., Napoli, E. \& Niccoli M., Conductometric and calorimetric studies of serially diluted and agitated solutions: the dependence of intensive parameters on volume. International Journal of Ecodynamics, 1, pp. 1-12, 2006.

[14] Elia, V., Elia, L., Montanino, M., Napoli, E., Niccoli, M. \& Nonatelli, L., Conductometric studies of the serially diluted and agitated solutions on an anomalous effect that depends on the dilution process. Journal of Molecular Liquids, 135, pp. 158-165, 2007. doi:10.1016/j. molliq.2006.11.005

[15] Elia, V., Napoli, E., Niccoli, M., Marchettini, N. \& Tiezzi, E., New physico chemical properties of extremely diluted solutions. A conductivity study at $25^{\circ} \mathrm{C}$ in relation to ageing. Journal of Solution Chemistry, 37, pp. 85-91, 2007. doi:10.1007/s10953-007-9215-5

[16] Belon, P., Elia, V., Elia, L., Montanino, M., Napoli, E. \& Niccoli, M., Conductometric and calorimetric studies of the serially diluted and agitated solutions. On the combined anomalous effect of time and volume parameters. Journal of Thermal Analysis and Calorimetry, 93(2), pp. 459-469, 2008. doi:10.1007/s10973-007-8580-z

[17] Elia, V., Elia, L., Napoli, E. \& Niccoli M., On the stability of extremely diluted aqueous solutions at high ionic strength. A calorimetric study at 298 K. Journal of Thermal Analysis and Calorimetry, 92(2), pp. 643-648, 2008. doi:10.1007/s10973-007-8840-y 
[18] Ciavatta, L., Elia, V., Napoli, E. \& Niccoli, M., New physico-chemical properties of extremely diluted solutions. Electromotive force measurements of galvanic cells sensible to the activity of $\mathrm{NaCl}$ at $25^{\circ} \mathrm{C}$. Journal of Solution Chemistry, 37(8), pp. 1037-1049, 2008. doi:10.1007/ s10953-008-9299-6

[19] Lobyshev, V.I., Shikhlinskaya, R.E. \&, Ryzhikov, B.D., Experimental evidence for intrinsic luminescence of water. Journal of Molecular Liquids, 82, pp. 73-8, 2003. doi:10.1016/S01677322(99)00043-4

[20] Lobyshev, V.I., Solovey, A.B. \& Bulienkov, N.A., Computer construction of modular structures of water. Journal of Molecular Liquids, 106, pp. 277-297, 2003. doi:10.1016/S0167-7322(03)00115-6

[21] Robinson, G.W., Cho, C.H. \& Gellene G.I., Refractive index mysteries of water. Journal of Physical Chemistry, 104, pp. 7179-7182, 2004. doi:10.1021/jp000913f

[22] Rey, L., Thermoluminescence of ultra-high dilutions of lithium chloride and sodium chloride. Physica A, 323, pp. 67-74, 2003. doi:10.1016/S0378-4371(03)00047-5

[23] Samal, S. \& Geckeler, K.E., Unexpected solute aggregation in water on dilution. Chem. Commun., pp. 2224-2225, 2001.

[24] Lo, S.Y., Anomalous state of ice. Modern Physics Letters B, 10, pp. 909-919, 1996. doi:10.1142/ S0217984996001036 doi:10.1142/S0217984996001048

[25] Lo S.Y., et al., Physical properties of water with IE structure. Modern Physics Letters B, 10, pp. 921-930, 1996. doi:10.1142/S0217984996001048 doi:10.1142/S0217984996001036

[26] Mishima, O. \& Stanley, H.E, Decompression-induced melting of ice IV and the liquid-liquid transition in water. Nature, 392, pp. 164-168, 1998. doi:10.1038/32386

[27] Malescio, G., Franzese, G., Skibinsky, A., Buldyrev, V., Sergey,V. \& Stanley, H.E, Liquidliquid phase transition for an attractive isotropic potential with wide repulsive range. Physical Review E, 71, 061504/1-061504/8, 2005.

[28] Woutersen, S. \& Bakker, H.J., Resonant intermolecular transfer of vibrational energy in liquid water. Nature, 402, pp. 507-509, 1999. doi:10.1038/990058

[29] Elia, V., Elia, L., Marchettini, N., Napoli, E., Niccoli, M. \& Tiezzi E., Physico-chemical properties of aqueous extremely diluted solutions in relation to ageing. Journal of Thermal Analysis and Calorimetry, 93(3), pp. 1003-1011, 2008. doi:10.1007/s10973-007-8843-8

[30] Hahnemann, Organon, 6th edn, RED, 1985.

[31] Iuliano, M., Ciavatta, L. \& De Tommaso G., Protolytic behaviour of hydroxylated Pyrex glass surfaces in $\mathrm{NaCl}$ media. Journal of Colloid Science, 310, pp. 402-410, 2007. doi:10.1016/j. jcis.2007.02.061

[32] Montagner, L., Aissa, J., Ferris, S.,Montagner, J.L. \& Lavallèe, C., Electromagnetic signals are produced by aqueous nanostructures derived from bacterial DNA sequences. Interdisciplinary Sciences: Computational Life Sciences, 1, pp. 81-90, 2009. doi:10.1007/s12539-009-0036-7

[33] Available online at: http://en.wikipedia.org/wiki/Microbial_cyst. 